\title{
Territórios pouco explorados: o estudo dos registros de visitantes em livros de comentários de dois museus de ciências brasileiros
}

Karlla Kamylla Passos dos Santos ${ }^{I}$ http://orcid.org/0000-0003-0419-2751

Jessica Norberto Rocha II

http://orcid.org/0000-0002-9754-3874

I Museu de Astronomia e Ciências Afins, RJ, Brasil.

Mestre em Divulgação da Ciência, Tecnologia e Saúde pela Fundação Oswaldo Cruz.

${ }^{I I}$ Instituto Nacional de Comunicação Pública da Ciência e Tecnologia, RJ, Brasil. Doutora em Educação pela Universidade de São Paulo.

http://dx.doi.org/10.1590/1981-5344/4343

Neste trabalho, de caráter qualitativo e exploratório, estudamos os livros de comentários de dois museus e centros de ciências brasileiros - a Casa da Ciência da Universidade Federal do Rio de Janeiro e o Museu Ciência e Vida da Fundação Centro de Ciências e Educação Superior a Distância do Estado do Rio de Janeiro - a fim de compreender e explorar seu potencial para coletar dados sobre a opinião dos públicos. Ao todo coletamos 1.724 comentários de 10 livros, do período de 2011 a 2018. Para exploração e análise, adotamos a análise de conteúdo, bem como um protocolo que divide os comentários em: pré-ativo, ativo e proativo. Nos interessou analisar os comentários apontados como ativos e proativos, totalizando em 1.512 registros, organizados nas seguintes categorias: acessibilidade; afetividade; ciência e aprendizagem; equipe; exposição; infraestrutura; papel dos espaços museológicos na 
sociedade.A multiplicidade de fatores que puderam ser elencados ao estudarmos os livros de comentários, nos permite afirmar que eles são uma rica fonte de informação a respeito dos públicos que frequentam os museus e suas demandas. Contudo, eles ainda são territórios pouco explorados, tanto nas instituições museais, quanto em áreas acadêmicas, e esses registros não podem ser silenciados e esquecidos.

Palavras-chave: livros de comentários; museus; estudos de público; divulgação científica.

\section{Underexplored territories: the study of visitor records in comment books of two Brazilians science museums}

In this qualitative and exploratory work, we studied the commentary books of two Brazilian museums and science centers- the Science House (Casa da Ciência) of the Federal University of Rio de Janeiro and the Science and Life Museum (Museu Ciencia e Vida) of the Center for Science and Higher Education at Distance Foundation of the State of Rio de Janeiro - in order to understand and explore its potential to collect data on publics opinions. We collected 1,724 comments from 10 books, from 2011 to 2018. For exploration and analysis, we adopted content analysis, as well as a protocol that divides comments into: pre-active, active and proactive. We were interested in analyzing the comments identified as active and proactive, totaling 1,512 records, organized into the following categories: accessibility; affectivity; science and learning; team; exhibition; infrastructure; role of museum spaces in society. The multiplicity of factors that could be listed when studying commentary books, allows us to affirm that they are a rich source of information about the audiences that go to museums and their demands. However, they are still underexplored territories, both in museums and in academic areas, and these records cannot be silenced and forgotten. 
Keywords: comments books; museums; audience study; science communication.

Recebido em 31.03.2020 Aceito em 01.09.2021

\section{Introdução}

Os estudos de público são fundamentais para o aprimoramento das práticas realizadas nos museus. Eles têm o potencial de demonstrar o que não funciona e desenvolver o que está tendo resultado positivo. Sua relevância é destacada em documentos oficiais brasileiros, como no Estatuto de Museus (BRASIL, 2009), que considera que esses estudos são uma importante fonte consultada pelas instituições ao elaborarem suas atividades, projetos e propostas para obtenção de recursos, manutenção de suas práticas educativas e exposições. Eles são fundamentais para que os espaços museológicos possam identificar sua audiência, ou seja, para quem estão realizando aquele trabalho, para quem objetivam realizá-lo, as potencialidades e limitações dos projetos.

Estudos de público são complexos e se apoiam em referenciais multidisciplinares; em parte, nas ciências sociais, museologia e educação museal, para interrogar sobre a dinâmica de atendimento do museu, as lógicas de difusão, formas de recepção e pluralidade dos usos dos espaços museológicos (EIDELMAN; ROUSTAN, 2014). Em outra parte, se sustentam nas ciências de administração e gestão para observar o mercado do lazer, "a concorrência entre os lugares de cultura, a mídia e o digital, e considera com atenção os processos de arbitragem em torno do tempo livre" (EIDELMAN; ROUSTAN, 2014, p. 13).

Para Koptcke (2005), os estudos de público não são recentes, embora sejam espaçados ao longo dos três séculos de existência das instituições museológicas. A autora também explica "por que" e "para que" pensar nos públicos: por serem eles o motivo da existência dos museus e principalmente pela importância de se conhecer para formular e reformular todos os processos museológicos. Assim, esse processo tem despertado o interesse da gestão das instituições, no sentido de que se deve "recolher dados relativos às experiências do visitante nas diferentes atividades do museu, em lugar de medir unicamente o êxito da exposição" (CAZELLI; COIMBRA, 2012, p. 3).

Os espaços museológicos também estão sendo fomentados a aprender a lidar com a heterogeneidade de seu público, que mudou ao longo dos anos (CAZELLI; COIMBRA, 2012) e tende a continuar mudando. 
A relação entre público e instituição é complexa, por envolver diversos fatores, dentre eles a forma como os museus foram estabelecidos no Brasil e no mundo; vivemos entre "transformações e permanências das práticas de apropriação dos museus pela sociedade, buscando identificar novas formas de uso e analisar os processos de formação dos públicos" (KOPTCKE, 2005, p. 186).

Antes espaços feitos por elites e para elites, desde a segunda metade do século XX, agora, no século XXI, embora gradativa, "uma relação mais próxima entre museus e sociedade vem sendo estimulada" (CAZELLI; COIMBRA, 2012, p. 3). Para Winter (2018), os museus passaram de ser totalmente focado em suas coleções para também serem focados em seus públicos. Por isso, cada vez mais museus querem e necessitam ouvir a opinião de seus visitantes. Schiele (2008) argumenta que:

O visitante de hoje quer ser ouvido e, mais que isso, querem ser atores e exercitar seu direito de voz. O resultado disso é uma profunda reavaliação da missão dos museus, da sua tradicional relação com a cultura e dos seus mediadores(SCHIELE, 2008, p. 36).

Dubuc (2011) defende que instituições museológicas têm atuado em problemas sociais, abrindo janelas para outras culturas. Tais espaços também estão sendo desafiados a "desempenhar um papel mais ativo na transformação, [...] atitudes e comportamentos sociais. Em todos os casos, as práticas dos museus têm mudado radicalmente" (DUBUC, 2011, p.497-498). Pohlman (2004) acredita que é preciso dar mais papeis ativos para o público para que essas transformações de fato aconteçam. No sentido de irem além de comprar ingressos, consumir informações e pagar impostos em dia, os públicos precisam ter mais oportunidades para fazerem conexões significativas entre a pesquisa científica e suas próprias vidas.

De acordo com Winter (2018), incorporar canais de comentários dos visitantes nas exposições pode tornar o museu mais inclusivo, tanto porque oferece a possibilidade de ter retornos sobre a instituição e sua infraestrutura, quanto por ser um canal para compreender a interpretação e recepção das exposições. Na primeira opção, abre um canal entre a instituição e seus públicos e representa uma fonte valiosa de pesquisa, ajudando a compreender a experiência do visitante, avaliar programas, dar insumos para planejamentos e políticas, documentar o trabalho do museu e embasar pedidos de financiamento. Na segunda opção, como uma ferramenta de interpretação, os canais de comentários dão ao 
visitante uma plataforma para se engajar com os temas da exposição e relaciona-los com seus conhecimentos e experiências pessoais, dando suporte, também,para as instituições compreenderem a produção de sentidos e processos de aprendizagem não formal dos públicos.

Os livros de comentários

Para saber as opiniões dos públicos que frequentam esses espaços, as instituições têm usado diversas estratégias, desde métodos mais tradicionais, como livros de comentários, até metodologias de tecnologia mais contemporânea, como equipamentos e aparatos interativos e canais e ferramentas online (WINTER, 2018).

Neste trabalho, damos enfoque aos livros de comentários, pois compreendemos que são potencialmente ricos em informações que ajudam o museu a ter informações sobre o público recebe e quais são as suas motivações, seus interesses, suas expectativas, suas opiniões, suas reclamações e suas necessidades.A pesquisa dos registros deixados nos livros de comentários não se restringe apenas à satisfação de quem visitou, é um momento para os públicos se expressarem da forma que the convir(BRASIL, 2009).

Os livros de comentários também podem ser chamados de cadernos e ser acompanhados da palavra 'visitante', e não 'comentários', entre outras variações na nomenclatura. Damos preferência, nesta pesquisa, para 'livro' devido à terminologia adotada no Estatuto de Museus (BRASIL, 2009). Embora no livro sejam colocadas sugestões e reclamações, optamos por considerá-las 'comentários', para uma visão geral

Os livros de comentários estão sendo utilizados por diferentes autores como fonte de informações e estudos sobre a experiência e as opiniões de visitantes. Moore e Brown (2007) analisou 2.500 comentários de livros da exposição itinerantes de 'Body Worlds', que passou por Japão, Alemanha, Viena, Suíça, Bélgica e Grã-Bretanha, Coréia, Taiwan, Canadá e Estados Unidos. O objetivo da referida pesquisa foi explorar os comentários dos visitantes relacionando a exposição a questões culturais, filosóficas e religiosas, a partir dos livros de comentários disponíveis ao sair da exposição. Os autores notaram que a maioria dos comentários tinham tom positivo e parabenizavam Gunther von Hagens (criador da técnica de plastinação e criador da exposição)e sua equipe, as instituições que financiaram, os doadores dos corpos e suas famílias e Deus pela fantástica experiência e pelas dissecações que informavam os visitantes e por fazer a exposição possível. Nas conclusões,Moore e Brown (2007) abordam que os comentários demonstram o desafio de fazer a educação científica, revelam a imagem do corpo como máquina e demonstram que as exposições promoveram, para muitos visitantes, um senso de comunidade entre toda a humanidade. 
Outra produção que analisou comentários dos públicos por escrito não em livros de comentários, mas em cartões- foi a das autoras Reich e Kollmann (2008). Elas elaboraram um protocolo para exploração desses cartões do Museu de Ciências de Boston, nos Estados Unidos, entre os anos de 2006 e 2007, e consideram que apesar do sistema de cartões de comentários não ter a capacidade de revelar todos os sentimentos da maioria dos visitantes, eles podem alertar para áreas onde é necessário mais trabalho para aumentar o conforto e a satisfação do visitante. Elas se debruçaram sobre os comentários e levantaram áreas que foram bemvistas dos visitantes (com base no baixo número de comentários negativos e um número elevado de comentários positivos) e áreas de preocupação (o que significa que receberam um grande número de comentários negativos) como: interações da equipe; acessibilidade; conforto; horários e segurança.

Ross (2017) estudou o livro de comentários do Museu Tribal Madhya Pradesh em Bhopal, na Índia, analisando seu potencial para fornecer informações sobre os visitantes de museus na Índia: suas expectativas e experiências, até sua consciência como cidadãos. A partir da análise, a autora apresenta os visitantes como especialistas e destaca que os registros dos livros estudados oferecem mais informações para gestores de museus e formuladores de políticas culturais do que para curadores.

Por fim, em uma produção recente, as italianas Magliacani, Madeo e Cerchiello (2018) estudaram os livros de comentários dos museus municipais do Castelo Viscontiem Pavia (Itália), como uma fonte de informação e um meio de diálogo.As autoras analisaram 630 comentários, registrados em 90 páginas do livro no período de cinco meses. Para isso elaboraram um protocolo para separar os comentários entre:1)pré-ativos:

aqueles registros que não trazem informações sobre a visita, que registram desenhos, assinaturas e deixam apenas seus dados biográficos (nome, nome e sobrenome, data de nascimento, proveniência geográfica); 2) ativos: registros sobre as coleções, exposições, dispositivos digitais e eletrônicos do museu, instalações e funcionários do museu, dentre eles podem comunicar um sentimento, uma opinião ou um julgamento sobre os mesmos itens.; 3)proativos: registros com sugestões de melhoria do museu, textos construtivos, recomendações concretas, críticas e manifestações sobre a relação do museu com a sociedade, cultura, ciência, etc. As autoras explicam que nesse estudo de caso, os comentários proativos foram proporcionalmente menores que os ativos. Contudo, suas sugestões importam para melhorar o serviço do museu e para o processo de avaliação. A partir dessa análise o estudo defende que - livro de comentários pode ser um meio de diálogo no campo dos estudos de público e enfatiza sua relevância a partir da perspectiva da gestão de museus. Partindo da ideia do museu como um espaço para o 
diálogo, na opinião das autoras, o livro deve ser considerado um instrumento relevante para estimular um público a refletir sobre a experiência da visita, sobre a gestão de museus e sobre o patrimônio cultural sociedade (MAGLIACANI, MADEO, CERCHIELLO, 2018)

A investigação sobre livros de comentários, especialmente em museus dedicados às temáticas científicas,entretanto, não é uma temática abordada com frequência em estudos de Museologia e Divulgação Científica no Brasil. Não obstante, todos estudos citados mostram que os livros de comentários são ferramentas potencialmente ricas para uma melhor escuta dos públicos presentes nas instituições.

Neste trabalho, de caráter qualitativo e exploratório, estudamos os livros de comentários de dois museus e centros de ciências brasileiros- a Casa da Ciência da Universidade Federal do Rio de Janeiro (CC/UFRJ) e o Museu Ciência e Vida da Fundação Centro de Ciências e Educação Superior a Distância do Estado do Rio de Janeiro (MCV/Cecierj) - a fim de compreender e explorar seu potencial para coletar dados sobre a opinião dos públicos.

\section{Universo de estudo: as instituições museológicas de ciências}

A Casa da Ciência (CC/UFRJ) é uma instituição museológica de ciências da Universidade Federal do Rio de Janeiro, fundada em 1995. Se apresenta como um centro de popularização da ciência por meio de exposições, oficinas, teatro e outros. Como disposto em seu site oficial, a CC/UFRJ entende como seu desafio e objetivo a motivação de visitantes, no sentido de fazerem suas descobertas, ter curiosidade $e$ questionamentos, dialogando com as ideias de autores como Wagensberg (2005) e Pires (2015). A CC/UFRJ está localizada no bairro Botafogo, uma área nobre e turística da cidade do Rio de Janeiro, com alto Índice de Desenvolvimento Humano (IDH).

O Museu Ciência e Vida (MCV/Cecierj) está aberto desde 2010 e foi oficialmente criado em 2011. Tem como missão popularizar e difundir Cultura, Ciência e Arte, e está vinculado à Fundação Centro de Ciências e Educação Superior a Distância do Estado do Rio de Janeiro (Cecierj), órgão da Secretaria de Ciência, Tecnologia e Inovação do Estado do Rio de Janeiro. O MCV/Cecierj está localizado em Duque de Caxias, a cidade mais populosa da Baixada Fluminense no Estado do Rio de Janeiro. Esta região, diferentemente da realidade da Casa da Ciência, não é uma área turística. Como explica Pires (2015, p.42), a região é marcada pelo "atraso social e educacional", uma vez que seu IDH revela "um baixo desenvolvimento econômico e escolar, com índices que mostram o resultado dos anos de abandono de políticas púbicas" (PIRES, 2015, p. 42). 


\section{Metodologia}

Esta pesquisa, de caráter exploratório e qualitativo, analisou os livros de comentários da Casa da Ciência/UFRJ e do Museu Ciência e Vida/Cecierj, do período de 2011 a 2018. Esse recorte temporal, inicial e final, foi escolhido por ser o momento em que ambas instituições disponibilizavam livros de comentários para o público. Ao todo coletamos 1.724 comentários (aqui considerados como unidade de análise) de 10 livros das duas instituições. Para exploração e análise desse material, adotamos como referencial teórico a análise de conteúdo de Bardin (1977).

A fase de organização dos dados da pesquisa, considerada por Bardin (1977) como a pré-análise e exploração, consistiu na sistematização dos comentários, de forma a compreender e ter um panorama geral das unidades de análise "de maneira a conduzir a um esquema preciso do desenvolvimento das operações sucessivas, num plano de análise" (BARDIN, 1977, p.121). Na fase seguinte, para a organização dos dados adotamos o protocolo de Magliacani, Madeo e Cerchiello (2018) que dividiram os comentários a partir do tipo de informações que eles ofereciam:pré-ativo, ativo e proativo, considerando que nos interessa para os estudos de público comentários apontados como ativos e proativos. Realizamos, então, a exclusão dos registros pré-ativos, totalizando em 1.512 unidades de análise.

Após a organização dos comentários ativos e proativos foi realizada a leitura flutuante - sempre com dupla análise às cegas das autoras para a formulação de categorias que emergiam desses dados e a elaboração de protocolos com descrições e exemplos (BARDIN, 1977). Algumas dessas categorias foram levantadas pelo grande número de menções como "exposição", "mediação" e "afetividade". Outras foram elencadas pela relevância temática na área da divulgação científica e em estudos de público em museus, mesmo não tendo tanta representatividade numérica, tais como: "acessibilidade", "divulgação científica" e "papel dos espaços museológicos na sociedade". Dessa forma, foi gerada por cada uma das autoras uma lista de primeiras categorias formuladas - o que Gibbs (2008) chama de potenciais necessários - para filtragem e construção. O aprofundamento das pesquisadoras nos dados e, a partir da categorização às cegas e o posterior confrontamento das categorias pré-estabelecidas foram ajustadas para melhor representar o universo estudado e sua análise. Assim, os comentários tiveram uma primeira categorização. Com seus resultados, pudemos mapear fragilidades, incoerências, repetições e o protocolo foi novamente ajustado.Finalmente, foi realizada a segunda categorização, considerada 
mais refinada do ponto de vista interpretativo- metodologia essa que Reich e Kollmam (2008) também realizaram.

Foram, então, definidas as seguintes categorias: 1) acessibilidade; 2) afetividade; 3) ciência e aprendizagem; 4) equipe; 5) exposição; 6) infraestrutura; 7) papel dos espaços museológicos na sociedade, conforme o quadro 1 descreve:

Quadro 1 - Categorias de análise e descrição

\begin{tabular}{|c|c|}
\hline Categoria & Descrição da categoria: Comentários que ... \\
\hline Acessibilidade & $\begin{array}{l}\text { Sugerem, critiquem ou elogiem especificamente } \\
\text { acessibilidade, uso e permanência de visitantes nos } \\
\text { museus e sua inclusão, além das deficiências. }\end{array}$ \\
\hline Afetividade & $\begin{array}{l}\text { Expressam emoções positivas e/ou negativas, seja por } \\
\text { meio de elogios, críticas e/ou agradecimentos. }\end{array}$ \\
\hline $\begin{array}{l}\text { Ciência e } \\
\text { aprend izagem }\end{array}$ & $\begin{array}{l}\text { Fazem referência a questões relacionadas à } \\
\text { aprendizagem e educação museal, divulgação científica } \\
\text { e temáticas científicas gerais e/ou específicas. }\end{array}$ \\
\hline Equipe & $\begin{array}{l}\text { Fazem menção à equipe do museu,de forma geral e/ou } \\
\text { específica, por exemplo, recepção, curadoria, e } \\
\text { mediadoras, entre outros. }\end{array}$ \\
\hline Exposição & $\begin{array}{l}\text { Fazem referência à curadoria e/ou seus módulos, } \\
\text { objetos e aparatos, comentário direto sobre a mostra. }\end{array}$ \\
\hline Infraestrutura & $\begin{array}{l}\text { Abordam o lugar e locais para alimentação, banheiros, } \\
\text { água, ar condicionado, equipamentos, módulos } \\
\text { expositivos e exposições em manutenção e/ou } \\
\text { estragadas, estrutura de maneira geral, positiva ou } \\
\text { negativamente. }\end{array}$ \\
\hline $\begin{array}{l}\text { Papel dos } \\
\text { espaços } \\
\text { museológicos } \\
\text { na sociedade }\end{array}$ & $\begin{array}{l}\text { Fazem menção à importância de espaços públicos de } \\
\text { disseminação e democratżação de conhecimento e } \\
\text { cultura, de forma direta ou indireta. }\end{array}$ \\
\hline
\end{tabular}

Fonte: autoria própria

\section{Resultados}

Na análise dos 1.512 comentários que se configuraram, segundo o protocolo de Magliacani, Madeo e Cerchiello (2018), como ativos e proativos, obtivemos: "Afetividade" com 809 comentários, "Equipe" com 505, "Exposição" com 441, "Ciência e aprendizagem" com 330, "Infraestrutura" com 279, "Acessibilidade" com 33 e "Papel dos espaços 
museológicos na sociedade" com 16, listados na tabela 2 e os quais discutimos e ilustramos a seguir.

Tabela 1 - Número de Comentários por Categoria*

\begin{tabular}{l|l}
\hline \multicolumn{1}{c|}{ Categorias $(\mathbf{N}=7)$} & Total \\
\hline Acessibilidade & 33 \\
\hline Afetividade & 809 \\
\hline Ciência e aprendizagem & 330 \\
\hline Equipe & 505 \\
\hline Exposição & 441 \\
\hline Infraestrutura & 279 \\
\hline Papel dos espaços museológicos na sociedade & 16 \\
\hline
\end{tabular}

Fonte: Tabela elaborada pelas autoras a partir dos acervos da CC/UFRJ e MCV/Fundação Cecierj. *Mais de uma categoria pode ser identificada em um mesmo comentário.

Vale destacar que mesmo que a nossa pesquisa se caracterize como essencialmente qualitativa, trazemos alguns números para contextualizar o leitor e nos apontar tendências no conjunto de dados. Outro fator que deve ser levado em consideração é que um mesmo comentário pode ser encaixado em mais de uma categoria, dada a complexidade e multiplicidade de elementos presentes nas opiniões dos públicos.

A categoria "Afetividade" se destacou em maior número - com 809 comentários categorizados. Esses registros expressaram, em sua maioria e maior representatividade,questões positivas por meio de elogios e/ou agradecimentos, demonstrando emoções e sinais considerados positivos como euforia, surpresa e confiança por parte de quem deixou comentários, como no comentário a seguir:

Adorei a exposição! Tô muito feliz de estar aqui, tá maravilhosa. Amei demais, fui atendida pelo mediador [nome] e foi muito bem atendido! Sucesso para ele e toda felicidade. Ele sabe atender e isso gera qualidade e satisfação em qualquer pessoa. Sucesso para a exposição e obrigada por me relembrarem os tempos em que era mediadora na exposição "Descubra e Divirta-se". Com amor (ago. 2017) 
Aspectos como surpresa "Eu achei muito legal, divertido e diferente e me surpreendeu" (jul. 2018); estímulo à curiosidade "Foi misturado e gera curiosidade. Parabéns pela iniciativa" (mai. 2012); hospitalidade "Estivemos aqui e fomos muito bem recebidos e a explicação da monitora [nome] foi excelente. Estão de parabéns" (mai. 2012), e gratidão

Fiquei maravilhada, encantada com o Pintor, com o local, com a disposição dos quadros, com a temática abaixo dos quadros expostos e principalmente com a explanação do mediador Sr. [nome]. Muito Obrigada por essa oportunidade e o empenho de todos em trazer nossa cultura e nosso pintor para o público(s/d, 2017)

também foram identificados, o que expressa uma gama bastante diversificada de emoções positivas sobre as visitas.

Os comentários também expressaram questões negativas relacionadas, por exemplo, má qualidade de algum serviço prestado, falta de acessibilidade, indignação, tédio, desânimo, decepção e raiva, como no exemplo que segue:

Que as crianças da Escola[nome da escola anonimizado] sejam tratadas com respeito pois as mesmas foram chamadas de "burra" durante a sessão do planetário. Eles se sentiram ofendidos e os professores também (ago. 2014).

Interessante notar que os comentários que demonstram sentimentos negativos, na maioria das vezes, vêm acompanhados de justificativas, manifestações de expectativas frustradas e/ou questões que se encaixam em outras categorias, o que reforça como a experiência é influenciada por um conjunto de fatores (da própria instituição e externos, bem como os de contexto sociocultural do visitante) que se somam e culminam em sentimentos e emoções. Um exemplo de comentário que demonstra tédio: "Achei um pouco monótono e eu fiquei com sono queria sugerir que tivesse mais interatividade. A exposição estava muito quente, poderia ter ar condicionado" (abr. 2012). Há, também, comentários evidenciando a decepção devido à quantidade de equipamento em manutenção: "Estive aqui para agendar uma visita e fiquei impressionada e triste com a quantidade de equipamento em manutenção. Lamentável isso, pois os estudantes não terão a experiência completa" (dez. 2016).

A segunda categoria com maior representação numérica foi "Equipe", com 505 comentários. Muitos deles abordaram a questão da mediação/equipe de acolhimento dos museus e nomenclaturas afins. Os 
públicos se referiram a esses profissionais, especialmente, no intuito de agradecer, pedir maior valorização para sua profissão e reclamar da sua ausência. Trazemos elogios à mediação nos exemplos: "Como não amar uma exposição de Portinari? E foi acertada a decisão pela mediação: [...] foi ótimo!" (dez. 2017) e

Parabéns a toda equipe envolvida no projeto, a exposição está extremamente didática para todas as faixas etárias. A mediação da informação também merece elogios, percebe pleno domínio do conhecimento informado pelos participantes, e me senti bem acolhida (jun. 2017)

Não somente elogios, mas também algumas críticas, foram encontradas, apesar de serem números significativamente menores, como a pessoa que sinalizou o mal-uso do celular, por parte das monitoras: "Adoramos as atividades propostas e as monitoras porém vale ressaltar que o uso do celular por parte das monitoras deveria ser proibido" (jun. 2015) e outra que sinalizou a importância de uma melhor distribuição da equipe no espaço expositivo: "A exposição é maravilhosa, mas é necessário a presença de monitor em cada espaço. Parabéns a monitora da cozinha! Ótima explicação! Continue assim" (mar. 2012).

Um dado que se destacou nessa categoria pelo número de ocorrências foi a diversidade de nomes usados pelos visitantes para se referir aos profissionais que trabalham no atendimento do público, dentre eles: 'monitores', 'guias', 'colaboradores', 'explicadores', 'instrutores', e outros mais peculiares como 'dinamizadores' - "Exposição muito interessante com dinamizadores de grande simpatia e conhecimento. Pretendo voltar com os meus alunos" (nov. 2017); 'intermediador' "Gostaria de agradecer ao intermediador [nome] que com certeza contribuiu e muito para a minha a obra" (nov. 2017). Tal fato reflete as várias facetas que esses profissionais exercem nos museus e, ao mesmo tempo, as inúmeras percepções do público a seu respeito.

Ainda na categoria "Equipe" também observamos alguns comentários deixados pelos próprios profissionais da instituição para tecer críticas à quantidade e organização de suas escalas, afetando o acolhimento dos públicos, como em: "Os mediadores estão sobrecarregados por conta da falta de outros integrantes. Estamos em 4 e tem muito público espontâneo. Isso faz com que haja família sem o nosso auxílio" (out. 2016). Esse fato envolve algo importante de ser pontuado: a exposição das questões internas da instituição em um livro que é de acesso e uso do público. Embora seja significativo que visitantes saibam das dificuldades enfrentadas por instituição museal, vale ponderar que talvez não havia uma facilidade na comunicação dos mediadores com a 
gestão do museu. Isso levou a essas pessoas fazerem um outro uso do instrumento de escuta dos públicos (especialmente): o registro de opiniões e demandas dos funcionários do museu que viram ali um canal de comunicação com instâncias superiores da instituição.

A terceira categoria com maior número de ocorrência, 441 comentários, foi relativo às questões expositivas gerais, "Exposição". Nela, constam os comentários das pessoas que parabenizam a curadoria, sugerem temas para futuras mostras, criticam a ausência de alguma informação sobre o tema proposto. Entre os comentários estão: "Fiquei 'emocionado' com tamanha perfeição e objetividade vindas dessa Exposição" (fev. 2012) e "A exposição "Movimente-se" estava excelente. A equipe organizadora está de parabéns" (set. 2015).

Localizamos comentários com críticas em relação ao conteúdo da mostra: tanto com relação ao seu conteúdo "Parabéns pela exposição. Realmente muito boa. Contudo, sempre a algo a melhorar. Todos os nomes dos polínios estão errados sugiro correção segundo nomenclatura oficial vigente. A disposição" (jun. 2012), quanto à criatividade e renovação das exposições "Venho por meio deste deixar ciente para o responsável da exposição, a falta de criatividade para novas exposições. Vendo que as mesmas já se encontram no espaço a muito tempo, sendo assim se tornando repetitiva. Grata!" (ago. 2015). Outros comentários fazem pedidos de abordagem de temática específicas e demonstram suas expectativas: "Sou a mãe da [nome da filha], me chamo [nome da mãe]; sempre que posso trago minha filha até o museu; as exposições são interessantes e educativas; mas eu gostaria de ver sobre: o carro, Monteiro Lobato, gostaria que minha filha desse mais valor à reciclagem" (ago. 2012).

Na categoria "Ciência e aprendizagem", em que categorizamos 330 comentários - a quarta categoria em termos de ocorrência -é evidenciada a preocupação dos públicos com a sua própria aprendizagem e a das crianças. Isso demonstra o quanto o museu e a aprendizagem estão constantemente relacionados no imaginário das pessoas que visitam esses locais, como é possível observar nos comentários a seguir:

O/A[nome do museu] é uma grande oportunidade para a sociedade se aproximar e conhecer grandes produções da área científica. E esta exposição vem mostrar isso, ainda mais que tem o papel de aproximar as crianças com conteúdos tão complexos como a eletricidade, mecânica, luz... Adorei a exposição e a disposição de com as coisas / experimentos estão. Obrigada equipe! Excelente trabalho (s/d. 2018) 
Essa é mais uma conquista de DC [Duque de Caxias]. As exposições são bem esclarecedoras. Quanto ao planetário podia ter se aprofundado em questões mais científicas. Mas valeu! Quanto a exposição são muito esclarecedoras e confrontam nossas atitudes. Sugiro que continuem assim! (s.d, 2014)

Ainda nessa categoria podemos destacar a relação de disciplinas escolares, como química e física, com a temática das exposições. Tal fato nos remete que há uma percepção desses visitantes da relação intrínseca dos museus com a escola. Temos como exemplo: "Adorei! Foi muito bom relembra o que estudei na escola. Física é o máximo!" (s.d 2018) e "Uma maneira superdivertida de ensinar a química para crianças, se eu fosse ensinada assim na época do ensino médio, com certeza nunca tivesse ficado de recuperação! Parabéns aos idealizadores do projeto; nota 1000" (s.d 2012).

A quinta categoria identificada foi "Infraestrutura", obtendo 279 comentários ao todo. Desses, alguns foram positivos, como "Eu adorei todos os cômodos da casa!!!!" (s.d), "O museu tem um espaço ótimo, extremamente organizado e a mediação nota 10! Parabéns!" (s.d 2014). Também notamos alguns comentários com sugestões, demonstrando que a pessoa, além de ter algum conhecimento sobre planetários, também tem vivência prévia em espaços museais: "Boa tarde. Eu gostaria de sugerir um refeitório ou cantina p/ lanches e também o projetor digital a qual nós sentimos uma grande diferença no planetário. Obrigada pela atenção" (jun. 2015).

Uma questão recorrente nos dois espaços foi o ar condicionado, particularmente por causa sua ausência, por exemplo: "Cadê o arcondicionado?" Podia ser o nome [da exposição]. Que calor! Mas fora isso, gostei. [...]" (mar. 2012) e "Adoramos a exposição! Gostaríamos de trazer nossos alunos. No entanto, o ar-condicionado ainda está fazendo muita falta. Parabéns pelo projeto!" (fev. 2012).

A "Acessibilidade" foi a sexta categoria que emergiu dos dados, com 33 comentários. Embora seja uma categoria com poucos escritos, sua presença é fundamental, por considerarmos uma questão relevante falarmos de públicos que demandam estratégias de acessibilidade para sua maior aproximação e frequência nos museus. Na maioria, eles reconheciam o esforço da instituição pela tentativa de promover a acessibilidade e a parabeniza por isso "Parabéns a todos por esse projeto tão importante e motivador, que valoriza a acessibilidade e propicia aos 
portadores de necessidades especiais estar participando e interagindo com o mundo de uma forma tão significante"(mai. 2012) e solicitavam maior acesso e permanência de públicos com deficiências "Faltou Libras!" (s.d 2018) e

Sou deficiente auditiva e não pude acompanhar a visita ao Planetário, uma vez que no escuro, não há como realizar a leitura labial sugiro a instalação de mecanismos de reprodução da fala do guia individuais, como pontos de escuta. Parabéns pela acessibilidade aos cadeirantes (jun. 2014).

A sétima categoria, a com a menor representatividade numérica, 16 comentários, mas não menos relevante, é "Papel dos espaços museológicos na sociedade". Comentários como "Essa visita contribui muito para a formação das pessoas! Parabéns! O Rio necessita de cultura!" (abr. 2012) e "Tenho o prazer de agradecer aos colaboradores deste espaço e eventos, pois é uma época já quase que muitas coisas estão extintas. Sugiro que museus como este continue o trabalho por muitos e muitos anos." (jan. 2015) observamos que os públicos se expressaram mais enfaticamente como cidadãos sobre a importância de as autoridades estarem mais atentas aos espaços culturais, fizeram críticas à forma como o governo gerencia seus recursos e o que se destina a museus e destacaram a importância da educação pública, gratuita e de qualidade aliada à cultura.

\section{Discussões}

No estudo de 10 livros de comentários, que conformam o período de 2011 a 2018, de dois museus de ciência brasileiros identificamos 1.724 registros, sendo 1.512 considerados ativos e proativos, segundo categorização de Magliacani, Madeo e Cerchiello (2018). A partir da análise de conteúdo desse material, emergiram sete categorias Acessibilidade; Afetividade; Ciência e Aprendizagem; Equipe; Exposição; Infraestrutura; Papel dos Espaços Museológicos na Sociedade -, o que nos dá elementos para argumentar que os livros de comentários possuem de fato um grande potencial para coletar dados sobre a opinião dos públicos que frequentam os museus de ciências.

No que diz respeito à natureza e ao estilo dos comentários vimos similaridades com a pesquisa de Ross (2017) que aponta que o público

usa uma ou duas frases, às vezes apenas algumas palavras para expressar seu entusiasmo, aprovação e alegria. Textos mais longos, em contraste, geralmente seguem um padrão 
definido: começando com elogios e levando a críticas ou sugestões(ROSS, 2017, p. 104).

Nossos dados também reiteram o que Morris (2011) defende: os livros de comentários funcionam como fóruns de liberdade de expressão.Assim, em consonância com Magliacani, Madeo e Cerchiello (2018) e Winter (2018), entendemos que os livros de comentários pode ser um meio de diálogo do museu com seus públicos e vice-versa.É possível, a partir da exploração e da análise dos registros dos livros, encontrar caminhos para ampliar a comunicação entre instituição e seus públicos, bem como aprimorar seu potencial de divulgação científica e comunicação da ciência. Mais que isso, Coffee (2013, p. 165) ainda destaca que os livros "são eventos dialógicos em si mesmos. Usuários do museu muitas vezes entram em uma experiência dialógica que envolve seu grupo visitante, o material exposto e o discurso dos mediadores do museu."

É importante salientar a valia desses enquanto uma forma de maior aproximação dos museus com as pessoas que os frequenta. Durante a análise, encontramos evidências de sentimentos positivos quanto à visita, como euforia, surpresa, estímulo à curiosidade, confiança, hospitalidade, mas também identificamos sinais de sentimentos negativos com relação à experiência museal. Todos eles têm grande potencial para indicar às instituições museais o que não funciona, aprimorar o que está sendo valorizado pelo público e atender a demandas específicas.

Nos nossos dados, há a valorização da instituição museal e dos profissionais que nela trabalham. Há também uma preocupação com o fator o coletivo em diversos comentários de categorias como 'Infraestrutura', no que diz respeito à falta de ar condicionado e que afetava não só os públicos, mas também funcionários e na categoria "Acessibilidade" sobre a presença e ausência de estratégias para a participação de diversos públicos. Similarmente isso aconteceu na categoria "Papel dos espaços museológicos na sociedade" e em comentários de 'Ciência e aprendizagem" que ressaltaram a relevância das instituições para a comunidade em que estão inseridas.

Com relação à diversidade de públicos desses museus, vale ressaltar que esse tipo de estudo possui algumas limitações, por exemplo, ter a opinião e estudar registros de públicos que foram pelo menos uma vez ao museu, letrados, e que por alguma razão se sentiram motivados a deixar seus comentários e opiniões em um instrumento institucional. Assim, é sempre relevante ter em mente - quando se trata de estudos de livros de comentários - que não se está fazendo um estudo de públicos, no sentido 
amplo da área, mas, sim, focado em um extrato do público da instituição museológica.

\section{Considerações finais}

Aquelas instituições museológicas que possuem o espaço para o registro das opiniões dos seus visitantes estão, de fato, à frente das demais quando pensamos nos canais de escuta e facilitação da comunicação entre instituição e visitantes - o que é o caso da Casa da Ciência/UFRJ e do Museu Ciência e Vida/ Cecierj, por nós estudados.

Nos livros de comentários estudados por Moore e Brown (2007, p.253) há o questionamento de um visitante que serve de mote para nossas considerações finais: "Fico me perguntando quem lê esses comentários?". Os autores de forma descontraída respondem que quem lê são acadêmicos como eles (e como nós!) e também alguns visitantes, como é o caso de um que deixou por escrito "Sempre acho esses livros de comentários interessantes - gosto da diversidade de opiniões mesmo que, com frequência, sejam insanos e feios, em vez de verdadeiras reflexões sobre o que as exposições fizeram com você" (MOORE; BROWN, 2007, p.253)

Fato é que esses comentários da pesquisa de Moore e Brown (2007) de certa formam coincidem com o que observamos nas nossas pesquisas: os livros de comentários -mesmo sendo interessantes, trazendo uma diversidade de opiniões - são territórios pouco explorados. Coffee (2013), Ross (2017) e Magliacani, Madeo e Cerchiello (2018) apontam que eles têm sido subutilizados e subanalisados pelos museus e pela literatura especializada.

Ainda existe a necessidade de os museus disponibiliza-los com regularidade para seu público, como é recomendado pelo Estatuto de Museus (BRASIL, 2009). Adicionalmente, mesmo quando eles existem, é necessário torna-los um canal de diálogo com o museu, bem como ter momentos e espaço institucionais para sua exploração e estudo para que gestores e a equipe dos museus possam conhecer o nível de satisfação dos seus públicos. As investigações desse (e sobre esse) material como objeto de estudo acadêmico ainda são escassas. Reconhecemos a necessidade de maiores e mais profundas discussões, levando em conta variados museus e exposições do país, tendo a possibilidade, inclusive, da criação de uma base de dados nacional de livros de comentários para ser analisada em nível local, regional e nacional.

A multiplicidade de fatores que puderam ser elencados ao estudarmos os livros de comentários de dois museus de ciências brasileiros, nos traz, por fim, a reflexão de que esses registros não podem 
ser silenciados, tampouco esquecidos. O que temos que assegurar na museologia e na divulgação científica, bem como em outras áreas de estudo, é que os públicos tenham o direito de se expressar, fazendo explícitas suas demandas, cobranças, agradecimentos, reclamações, comentários, observações e/ou apenas marcando seu lugar de fala no museu e na sociedade, como em registros de "eu estive aqui".

\section{Referências}

BARDIN, L. Análise de conteúdo. Lisboa: Edições 70. 1977.

BRASIL. LEI No 11.904, 14 de janeiro de 2009. Estatuto de Museus. Disponível em: http://www.planalto.gov.br/ccivil 03/ Ato20072010/2009/Lei/L11904.htm. Acesso: 11 de jul. 2015.

CAZELLI, S.; COIMBRA, C. A. Q. Pesquisas educacionais em museus: desafios colocados por diferentes audiências. In: WORKSHOP INTERNACIONAL DE PESQUISA EM EDUCAÇÃO EM MUSEUS, 1., 2012, dez.12 14: São Paulo, SP. Anais [...] São Paulo: Faculdade de Educação da USP, 2012. 1 CD-ROM. Disponível em: http://www.geenf.fe.usp.br/v2/wpcontent/uploads/2013/01/Mesa 1 Cazell i-protegido.pdf. Acesso em: 09 de jun. 2019.

CAZELLI, S.; COIMBRA, C. A. Q. Avaliação formal na educação não formal. Associação Brasileira de Avaliação Educacional - ABAVE, Rio de Janeiro RJ, 18 a 20 de junho de 2008. Disponível em:

http://www.fiocruz.br/omcc/media/EVCV CAZELLI COIMBRA Avalicao fo rmal na educacao nao formal.pdf. Acesso em: 22 de mar. 2013.

COFFEE, K. Visitor Comments as Dialogue. Curator: The Museum Journal, v. 56, n.2, p. 163-167, 2013. Doi: 10.1111/cura.12017

DUBUC, E. Museum and university mutations: the relationship between museum practices and museum studies in the era of interdisciplinarity, professionalisation, globalisation and new technologies, Museum Management and Curatorship, v.26, n.5, p. 497-508, 2011.

EIDELMAN, J.; ROUSTAN, M. Os Estudos Sobre Público: Pesquisa Fundamental, Escolha de Políticas e Apostas Operacionais. In: EIDELMAN, Jacqueline; ROUNSTAN, M.; GOLDSTEIN, B. (Org.). O lugar do público: sobre o uso de estudos e pesquisa pelos museus. Tradução: Ana Goldeberger. São Paulo: Iluminuras: Itaú Cultural, 2014. p. 13-40.

GIBBS, G. Análise de Dados Qualitativos. Portuguese language translation by Artmed, 2009. Obra originalmente publicada sob título Analyzing Qualitative Data. London, New Delhi and Singapore: SAGE, 2008. 
KOPTCKE, L. S. Bárbaros, escravos e civilizados: o público dos museus no Brasil. In: CHAGAS, M. S. (Org.) Museu: antropofagia da memória e do patrimônio - Revista do Patrimônio Histórico e Artístico Nacional, n. 31, Rio de Janeiro: Instituto do Patrimônio Histórico e Artístico Nacional, 2005, p. 184-205.

KÖPTCKE, L. S. Público, o X da questão? A construção de uma agenda de pesquisa sobre os estudos de público no Brasil. Museologia \& Interdisciplinaridade. Revista do Programa de Pós-Graduação em Ciência da Informação da Universidade de Brasília. v.1, n.1, jan./jul., 2012.

MAGLIACANI, M.; MADEO, E.; CERCHIELLO, P. From 'listener' to 'speaker' museum visitors: guest book as a means of dialogue. Museum Management and Curatorship, v. 33, n. 5, p. 467-483, 2018. Doi: 10.1080/09647775.2018.1506709.

MOORE, C. M.; BROWN, C. M. Experiencing Body Worlds: Voyeurism, Education, or Enlightenment? J Med Humanit, v.28, n.4, p.231-54, Jan. 2008

MORRIS, B. J. The Frightening Invitation of a Guestbook. Forum, v. 54, n. 3. July, 2011.

PIRES, A. M. G. Expectativas e vivências dos professores ao visitarem o Museu Ciência e Vida. Dissertação (Mestrado em Museologia e Patrimônio) - Programa de Pós-Graduação em Museologia e Patrimônio, Universidade Federal do Estado do Rio de Janeiro - UNIRIO; Museu de Astronomia e Ciências Afins - MAST, Rio de Janeiro, 2015.

POHLMAN, D. Not so Fast: Some Thoughts on Re-visioning PUR. In: CHITTENDEN, D.; FARMELO, G.; LEWENSTEIN, B. Creating connections. Museums and the public understanding of current research. Walnut Creek: Alta Mira Press, 2004, p. 329-336.

REICH, C.; KOLLMANN, E. K. A. Closer Look at the Visitor Experience: An Analysis of Visitor Comment Cards Evaluation Report. Museum of Science, Boston National Center for Technological Literacy. National Center for Technological Literacy. January 2008, p. 1-38.

ROSS, I. Uncharted territory: Visitor books of Indian museums. The Madhya Pradesh Tribal Museum in Bhopal - a case study. Museum \& Society, v. 15, n.1, 2017. 
SCHIELE, B. Science museums and centers. In: BUCCHI, M.; TRENCH, B. Handbook of Public Communication of Science and Technology. First Edition NY: Routledge, 2008.

WAGENSBERG, J. The "total" museum, a tool for social change. In:

História, Ciências e Saúde: Manguinhos, v. 1, n. 1 (1994). Rio de Janeiro: Fundação Oswaldo Cruz, Casa de Oswaldo Cruz, 2005.

WINTER, M. Visitor perspective on commenting in museums. Museum Management and Curatorship, v. 33, n. 5, p. 484-505.

\section{Agradecimentos:}

A primeira autora agradece à Fundação Oswaldo Cruz pela concessão de bolsa para realização desta pesquisa. A segunda autora é Jovem Cientista do Nosso Estado FAPERJ e agradece à agência pelo fomento. 